\title{
Activity of paraoxonase 1 (PON1) and its relationship to markers of lipoprotein oxidation in healthy Slovaks
}

\author{
Katarína Sumegová1, Pavel Blažíček ${ }^{2}$, Iveta Waczulíková3 ${ }^{1}$ Ingrid Žitňanová ${ }^{1}$ and \\ Zdeňka Ďuračková1凶
}

\begin{abstract}
${ }^{1}$ Department of Medical Chemistry, Biochemistry and Clinical Biochemistry, School of Medicine, Comenius University, Bratislava, Slovakia; ${ }^{2}$ Division of Biochemical Clinical Laboratories, Hospital of Ministry of Defence, Bratislava, Slovakia; ${ }^{3}$ Department of Nuclear Physics and Biophysics, Division of Biomedical Physics, Faculty of Mathematics, Physics and Informatics, Comenius University, Bratislava, Slovakia;

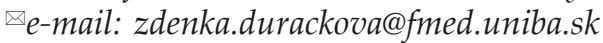

Received: 17 March, 2006; revised: 05 October, 2006; accepted: 16 October, 2006

available on-line: 14 November, 2006

\begin{abstract}
Low-density lipoproteins (LDLs), when modified by free radicals derived from artery wall cells, induce atherosclerosis. In contrast to oxidized LDL (ox-LDL), high-density lipoproteins (HDLs) are able to prevent atherosclerosis through a protein with antioxidant properties, paraoxonase 1 (PON1). The purpose of this study was to explore the association between the activity of HDL-associated PON1 and circulating ox-LDL as well as to investigate the relationship between ox-LDL and parameters of lipid profile in thirty Slovaks aged 21-73 years because recent studies have presented controversial results concerning PON1 and its role in LDL oxidation. For determination of circulating ox-LDL sandwich ELISA was used and other lipid parameters were determined by routine laboratory analyses. PON1 activities were assayed by two synthetic substrates - paraoxon and phenyl acetate. Lipid peroxides were determined spectrophotometrically. Of the lipid parameters examined, ox-LDL level correlated positively with total $(P<0.0001)$ and LDL-cholesterol $(P$ $<0.001)$. Triacylglycerols $(\mathrm{TAG})(P<0.001)$, lipid peroxides $(P<0.01)$ and atherogenic index (AI $=$ total cholesterol/HDL $)(P<0.0001)$ were also strongly correlated with ox-LDL. No inverse relationships were observed between ox-LDL and HDL-cholesterol or arylesterase/paraoxonase activities of PON1. Furthermore, it was found that ox-LDL $(P<0.01)$ and lipid peroxides $(P<0.05)$ were significantly higher in men than in women. PON1 arylesterase activity was marginally affected by sex. The results of this study suggest that the anti-atherogenic properties of HDLs are not directly related to their total concentration and that PON1 activity determined towards synthetic compounds (paraoxon and phenyl acetate) reflects no association with markers of oxidative stress. Furthermore, it follows from our results that men are more susceptible to developing atherosclerosis compared to women.
\end{abstract}

Keywords: atherosclerosis, HDL, ox-LDL, paraoxonase 1

\section{INTRODUCTION}

Atherosclerosis is a long-term inflammatory disorder affecting the inner walls of arteries with a great number of predisposing factors such as age, sex, diabetes mellitus, physical inactivity and obesity, cigarette smoking or hypertension. It is characterized by endothelial dysfunction, increased permeability of endothelium to lipoproteins, migration of white blood cells into the walls of arteries, as well as necrosis. LDL particles modified by free radicals are believed to play a critical role in atherosclerosis development. They induce atherosclerosis by stimulating monocyte infiltration and smooth muscle cell migration and proliferation (Mertens \& Holvoet, 2001). The presence of oxidatively modified LDL has been evidenced in atherosclerotic lesions of animals such as rabbits (Ylä-Herttuala et al., 1989) as well as in humans. Holvoet et al. (1998) found that ox-LDL was related to coronary artery disease. Moreover,

Abbreviations: AI, atherogenic index; BMI, body mass index; HDL, high-density lipoprotein; I.R., interquartile range; LDL, low-density lipoprotein; ox-LDL, oxidized LDL; PON1, paraoxonase 1; TAG, triacylglycerols. 
observations reported by Hulthe and Fagerberg (2002) confirmed an association between subclinical atherosclerosis and ox-LDL by finding that ox-LDL level was related to intima-media thickness.

It is supposed that LDL particles can be protected from free radical-induced oxidation by an HDL linked enzyme, paraoxonase 1 (PON1). PON1 is found in tissues such as liver, kidney, intestine, and also serum (Aviram et al., 1998) and its activity is calcium dependent. It may possess anti-atherogenic and anti-inflammatory properties, resulting from its ability to destroy modified phospholipids and to prevent cumulation of oxidized lipids in lipoproteins, although the precise mechanism of PON1 effect is not yet completely known. Moreover, the reference values of PON1 activities require validation. A variety of external factors, such as antioxidant- or cholesterol-rich diet and lifestyle, can positively as well as negatively influence the activity of human PON1.

Evidence that PON1 is involved in the attenuation of atherosclerosis has mainly been obtained from animal studies. In studies with mice it was shown that PON1-deficient mice were more susceptible to atherosclerosis than wild-type littermates (Gouédard et al., 2003). In human studies, an inverse relationship between PON1 activity and several pathologies associated with atherosclerotic disease such as familial hypercholesterolemia (Mackness et al., 1991; Tomás et al., 2000) or diabetes mellitus type I (Mackness et al., 2002) have been reported.

The aim of this study was to investigate the relationship between the marker of atherosclerosis - ox-LDL - and the activity of the potentially anti-atherogenic enzyme PON1 determined towards paraoxon and phenyl acetate. Thirty Slovak individuals of European lifestyle were investigated.

Additionally, associations between ox-LDL level and parameters of lipid profile were studied in these subjects.

\section{PATIENTS AND METHODS}

Patients and sample preparation. Thirty clinically healthy subjects ( 21 females and 9 males; average age: $41.3 \pm 2.9$; range: $21-73$ years) were studied. All participants gave a written consent to participate in our study. Four individuals were active or occasional smokers.

Blood was taken from vein into commercial tubes (Sarstedt). After centrifugation (10 $\mathrm{min}$ at 1200 $\times g$ ) serum was immediately separated and stored in aliquots at $-80^{\circ} \mathrm{C}$ until use.

Determination of ox-LDL. Circulating oxLDL in serum was measured by Mercodia Oxidized LDL ELISA kit (Uppsala, Sweden) on a Biorad au- toanalyser (Roche, Switzerland) according to the producer's instructions. Results are expressed in arbitrary units as U/L.

Determination of lipid parameters. Total cholesterol, HDL-cholesterol and triacylglycerols were determined by standard biochemical procedures using a Hitachi 911 automatic analyser (Roche, Switzerland). LDL was calculated according to the equation of Friedewald et al. (1972).

Determination of PON1 arylesterase activity. For the determination of PON1 arylesterase activity in serum, phenyl acetate was used as a synthetic substrate according to Gan et al. (1991) with slight modification. The assay mixture contained $100 \mu \mathrm{L}$ of $10 \mathrm{mmol} / \mathrm{L}$ substrate solution, $5 \mu \mathrm{L}$ serum and 1 $\mathrm{mmol} / \mathrm{L} \mathrm{CaCl}_{2}$ (Sigma, USA) in $50 \mathrm{mmol} / \mathrm{L}$ Tris buffer (Fluka Chemie, Switzerland), pH 8. Production of phenol was determined spectrophotometrically after $2 \mathrm{~min}$ at $270 \mathrm{~nm}$ (Biochrom 4060 spectrophotometer, Cambridge, UK). The assay mixture was prepared daily before use. PON1 arylesterase activity was monitored in triplicate and the results are presented as $\mu \mathrm{mol} / \mathrm{min}$ per $\mathrm{mL}$. Mean intra-assay and inter-assay coefficients of variation were up to $5 \%$ and $8 \%$, respectively.

Determination of PON1 paraoxonase activity. For measurement of PON1 paraoxonase activity in serum, paraoxon (Sigma, USA) was used as a synthetic substrate according to Beltowski et al. (2002) with some modifications. After addition of $3.3 \mathrm{mmol} / \mathrm{L}$ substrate to the assay mixture containing $10 \mu \mathrm{L}$ of serum and $1 \mathrm{mmol} / \mathrm{L} \mathrm{CaCl}_{2}$ (Sigma, USA) in $20 \mathrm{mmol} / \mathrm{L}$ Tris/buffer, $\mathrm{pH} 8$, formation of p-nitrophenol was monitored spectrophotometrically at $412 \mathrm{~nm}$ for $3 \mathrm{~min}$. PON1 paraoxonase activity was determined in triplicate and all results are presented in $\mathrm{nmol} / \mathrm{min}$ per $\mathrm{mL}$. Mean intra-assay and inter-assay coefficients of variation for this analysis were $13.3 \%$ and $10.9 \%$, respectively.

Determination of lipid peroxides. Serum lipid peroxides were assayed spectrophotometrically (Opton PM2 DL) according to El-Saadani et al. (1989). The analysis was based on the ability of lipid peroxides to convert iodide to iodine. Briefly, the reaction was initiated by addition of serum $(100 \mu \mathrm{L})$ to the assay mixture prepared according to the ElSaadani's protocol. After $30 \mathrm{~min}$ total amount of lipid peroxides was monitored at $365 \mathrm{~nm}$. All results are presented in nmol per $\mathrm{mL}$ of sample. Mean intra-assay coefficient of variation for this analysis was lower than $5 \%$.

Statistical analysis. Results are presented as mean \pm standard error of mean (S.E.M.) or median (interquartile range, I.R.). Student's unpaired $t$-test and Mann-Whitney U-test were used for statistical analysis of data with a gaussian and nongaussian distribution. $P<0.05$ was considered to be statisti- 
cally significant. StatsDirect ${ }^{\circledR} 2.3 .7$ (Stats Direct Sales, Sale, Cheshire M33 3UY, UK) was used for all correlation analyses. The strength of the association between two investigated parameters was expressed by the Pearson's product moment and Spearman's correlation coefficients.

\section{RESULTS}

Table 1 summarizes clinical and biochemical parameters of subjects participating in our study.

We found that the subjects, who were randomly selected for this study, had an increased mean level of total cholesterol (from 4.44 to 8.43 $\mathrm{mmol} / \mathrm{L}$ ) and TAG (from 1.04 to $4.34 \mathrm{mmol} / \mathrm{L}$ ) compared to reference values. Other mean parameter values of lipid metabolism (HDL- and LDL-cholesterol) (Table 1) were in the range of physiological values (from 0.72 to $2.17 \mathrm{mmol} / \mathrm{L}$ and from 2 to 6.6 $\mathrm{mmol} / \mathrm{L}$, respectively). Serum ox-LDL level in the study subjects ranged from 45.47 to $152.67 \mathrm{U} / \mathrm{L}$ with the mean value of $90.08 \pm 4.95 \mathrm{U} / \mathrm{L}$. Median (interquartile range) of the total amount of lipid peroxides was $41.85(36.08,77.84) \mathrm{nmol} / \mathrm{mL}$. PON1 arylesterase activity in the subjects ranged from 49.79 to 121.03 $\mu \mathrm{mol} / \mathrm{min}$ per $\mathrm{mL}$ (mean: $86.04 \pm 3.26 \mu \mathrm{mol} / \mathrm{min}$ per $\mathrm{mL}$ ). Median (interquartile range) of PON1 paraoxonase activity was $61.64(29.61,146.35) \mathrm{nmol} / \mathrm{min}$ per $\mathrm{mL}$. For ox-LDL, lipid peroxides, and PON1 arylesterase/paraoxonase activities the reference range is not known.

\section{Ox-LDL, lipid peroxides and PON1 activity}

The associations between ox-LDL or lipid peroxides and both PON1 arylesterase and paraoxonase activities were examined in the study group by Pearson's correlation and Spearman's rank correlation.
Surprisingly, the values for ox-LDL level as well as lipid peroxides were not correlated with PON1 arylesterase activity $(\mathrm{r}=-0.207, P=0.272, \mathrm{n}=$ $30 ; \mathrm{r}=0.015, P=0.936, \mathrm{n}=30$, respectively). A similar result was also obtained for PON1 paraoxonase activity in relation to ox-LDL and lipid peroxides ( $\mathrm{r}$ $=-0.084, P=0.657, \mathrm{n}=30 ; \mathrm{r}=-0.146, P=0.438, \mathrm{n}=$ 30 , respectively) where the strength of the association between both parameters was even lower.

\section{Ox-LDL and parameters of lipid metabolism}

The relationship between ox-LDL level and parameters of lipid metabolism was also studied. As shown in Table 2, a positive correlation between ox-LDL and total cholesterol was observed $(\mathrm{r}=$ 0.755, $P<0.0001, \mathrm{n}=30$ ). Similar associations were found for calculated LDL $(\mathrm{r}=0.644, P=0.0002, \mathrm{n}$ $=30)$ and TAG $(\mathrm{r}=0.609, P=0.0004, \mathrm{n}=30)$. Additionally, significant relations were found between ox-LDL and atherogenic index AI (AI = total cholesterol/HDL) $(\mathrm{r}=0.756, P<0.0001, \mathrm{n}=30)$ or lipid peroxides $(\mathrm{r}=0.499, P=0.005, \mathrm{n}=30)$. On the other hand, only a negative tendency between ox-LDL and HDL was found $(\mathrm{r}=-0.343, P=0.064, \mathrm{n}=30)$.

\section{Sex and markers of atherosclerosis}

Ox-LDL was significantly higher $(P=0.002)$ in men than in women (Table 3 ). The mean value of ox-LDL in men was about one third higher compared to women. The amount of lipid peroxides was immensely higher in men in comparison to women $(P=0.019)$.

As expected, PON1 arylesterase activity was lower in men than in women, but this difference was only marginally significant $(P=0.056)$. PON1 paraoxonase activity was not different between sexes $(P=0.594)$.

\section{Table 1. General and biochemical characteristics of subjects.}

Data are expressed as mean \pm S.E.M. except PON1 paraoxonase activity, lipid peroxides and TAG, which are presented as median (interquartile range, I.R.), the number of subjects in our study $=30$, R.V. means reference values determined in our laboratory.

\begin{tabular}{|c|c|c|c|}
\hline Parameters & Mean \pm S.E.M. & Median (I.R.) & R.V. \\
\hline Age & $41.33 \pm 2.91$ & & \\
\hline Serum ox-LDL (U/L) & $90.08 \pm 4.95$ & & No R.V. \\
\hline Lipid peroxides $(\mathrm{nmol} / \mathrm{mL})$ & & $41.85(36.08,77.84)$ & No R.V. \\
\hline PON1 arylesterase activity $(\mu \mathrm{mol} / \mathrm{min}$ per $\mathrm{mL})$ & $86.04 \pm 3.26$ & & No R.V. \\
\hline PON1 paraoxonase activity ( $\mathrm{nmol} / \mathrm{min}$ per $\mathrm{mL}$ ) & & $61.64(29.61,146.35)$ & No R.V. \\
\hline Total cholesterol (mmol/L) & $5.58 \pm 0.20$ & & $<5.17$ \\
\hline HDL-cholesterol (mmol/L) & $1.15 \pm 0.06$ & & $0.9-1.84$ \\
\hline LDL-cholesterol (mmol/L) & $3.44 \pm 0.19$ & & $<3.5$ \\
\hline TAG (mmol/L) & & $2.15(1.76,2.69)$ & $<2.0$ \\
\hline
\end{tabular}


Table 2. Correlation coefficients between ox-LDL and parameters of lipid profile in healthy subjects.

AI $($ atherogenic index $)=$ total cholesterol/HDL. Pearson correlation was used to evaluate the degree of associations between ox-LDL and total cholesterol. Non-parametric Spearman correlation was used to test the associations between ox-LDL and other variables (HDL- and LDL-cholesterol, TAG, AI and lipid peroxides). ${ }^{* *} P<0.01,{ }^{* * *} P<0.001$.

\begin{tabular}{lll}
\hline Parameter & ox-LDL & \\
\hline & $\mathrm{r}$ & Significance level $(P)$ \\
\hline Cholesterol & & \\
$\quad$ Total & 0.755 & $* * *$ \\
HDL- & -0.343 & 0.064 \\
LDL- & 0.644 & $* * *$ \\
TAG & 0.609 & $* * *$ \\
AI & 0.756 & $* * *$ \\
Lipid peroxides & 0.499 & $* *$ \\
\hline
\end{tabular}

\section{DISCUSSION}

Only few studies have found a significant association between the level of ox-LDL and parameters of lipid profile. Sigurdardottir and co-workers (2002) found that ox-LDL is associated with factors of metabolic syndrome such as triacylglycerols, BMI or HDL-cholesterol. Similar results were found by other researchers who reported relationships between ox-LDL and hypercholesterolemia, BMI, age, triacylglycerols, HDL and LDL in selected populations (Holvoet et al., 2001; Kondo et al., 2001).

In this study we report similar findings, although no significant correlation between ox-LDL and HDL was observed. No significant correlation between both parameters in healthy subjects was also observed by Toshima et al. (2000), who used a different type of capture antibodies.

The results of many studies performed in vitro and in vivo suggest that the activity or concentration of PON1 is inversely associated with atherosclerotic processes, in which ox-LDL plays a significant role. In this study we observed no associations between circulating ox-LDLs and arylesterase/paraoxonase activities of PON1 in healthy volunteers. Our inability to observe associations between the activity of PON1 and markers of lipid oxidation could be partly explained by the heterogeneity of the study group with respect to sex, age or profile of lipid metabolism, genetic polymorphism or a small number of individuals included in our study as well as by the fact that PON1 activity determined towards synthetic compounds (in our case phenyl acetate and paraoxon) needs not necessarily correlate with its antioxidant ability.

On the other hand, recent studies have demonstrated that PON1 may not be able to protect LDL from oxidation in vitro as well as in vivo. Teiber et al. (2004) found that purified serum PON1 does not protect LDL against oxidation in in vitro assays initiated with copper or a free radical generator, 2,2'azobis-2-amidinopropane hydrochloride (AAPH). Similarly, Sampson et al. (2005), who studied associations between PON1 activity and ox-LDL concentration in individuals with diabetes type II, found no relation between these study variables except the relationship of ox-LDL levels and PON1 arylesterase activity in diabetic males. Therefore, that study did not confirm an in vivo beneficial PON1 action in LDL oxidation, either. Because of this discrepancy of results it is necessary to perform a study with a higher number of participants.

As expected, we found that ox-LDL was significantly higher in men compared with women. This finding could support the assumption of a lower incidence of atherosclerosis and cardiovascular diseases in women. It is postulated that estrogens may be responsible for this phenomenon. Because estrogen (estradiol) is a phenol (Parthasarathy et al., 2000), it may participate with other antioxidants in the protection against atherosclerosis. Furthermore, estrogen increases vasodilatation and inhibits the response of blood vessels to injury (Topçuoğlu et al., 2005).

In summary, the present study showed associations between ox-LDL and two traditional risk factors of atherosclerosis (LDL and TAG) as well as atherogenic index (total cholesterol/HDL ratio) in

Table 3. Ox-LDL and other parameters associated with atherosclerosis with respect to sex.

All results are expressed as mean \pm S.E.M. except PON1 paraoxonase activity and lipid peroxides, which are presented as median (interquartile range) ${ }^{\dagger}$. Differences in ox-LDL and PON1 arylesterase activity between sexes were analysed by Student's unpaired $t$-test. For comparison of PON1 paraoxonase activity and lipid peroxides between the two groups, non-parametric Mann-Whitney U-test was used. ${ }^{*} P<0.05,{ }^{* *} P<0.01$.

\begin{tabular}{llll}
\hline Parameter & Men & Women & Significance level \\
& $(\mathrm{n}=9)$ & $(\mathrm{n}=21)$ & $*$ (P) \\
\hline Serum ox-LDL $(\mathrm{U} / \mathrm{L})$ & $112.16 \pm 7.29$ & $80.61 \pm 5.16$ & 0.056 \\
PON1 arylesterase activity $(\mu \mathrm{mol} / \mathrm{min}$ per $\mathrm{mL})$ & $76.59 \pm 6.29$ & $90.09 \pm 3.54$ & 0.594 \\
PON1 paraoxonase activity $(\mathrm{nmol} / \mathrm{min}$ per $\mathrm{mL})$ & $55.87(32.80,181.61)^{\dagger}$ & $80.15(27.33,118.74)+$ & $*$ \\
Lipid peroxides $(\mathrm{nmol} / \mathrm{mL})$ & $139.27(41.30,157.72)^{\dagger}$ & $38.86(33.74,50.81) \dagger$ & $*$ \\
\hline
\end{tabular}


healthy Slovak volunteers. Moreover, it also confirmed the concept that men are more susceptible than women to ox-LDL production as well as lipid peroxides formation and therefore to development of atherosclerosis. Additionally, the results of this study showed that PON1 activity towards synthetic substrates does reflect no relationship to oxidative stress characterised by its markers (ox-LDL and lipid peroxides). However, this finding needs further investigation.

\section{Acknowledgements}

This study was supported by VEGA grant $1 / 1157 / 04$ of the Ministry of Education of SR, $\mathrm{UK} / 28 / 2004$ grant of Comenius University and the Mind \& Health-civil Association. The authors wish to thank Dr. Bianca Fuhrman from the Lipid Research Laboratory, Technion Faculty of Medicine and Rambam Medical Center (Haifa, Israel) for her useful comments and help with introduction of the PON1 method.

\section{REFERENCES}

Aviram M, Rosenblat M, Bisgaier ChL, Newton RS, PrimoParmo SL, La Du BN (1998) Paraoxonase inhibits highdensity lipoprotein oxidation and preserves its functions. A possible peroxidative role of paraoxonase. J Clin Invest 101: 1581-1590.

Beltowski J, Wójcicka G, Marciniak A (2002) Species- and substrate-specific stimulation of human plasma paraoxonase 1 (PON1) activity by high chloride concentration. Acta Biochim Polon 49: 927-936.

El-Saadani M, Esterbauer H, El-Sayed M, Goher M, Nassar AY, Jürgens G (1989) A spectrophotometric assay for lipid peroxides in serum lipoproteins using a commercially available reagent. J Lipid Res 30: 627-630.

Friedewald WT, Levy RI, Fredrickson DS (1972) Estimation of the concentration of low-density lipoprotein cholesterol in plasma without use of the preparative ultracentrifuge. Clin Chem 18: 449-502.

Gan KN, Smolen A, Eckerson HW, La Du BN (1991) Purification of human serum paraoxonase/arylesterase. Evidence for one esterase catalyzing both activities. Drug Metab Dispos 19: 100-106.

Gouédard C, Koum-Besson N, Barouki R, Morel Y (2003) Opposite regulation of the human paraoxonase-1 gene PON-1 by fenofibrate and statins. Mol Pharmacol 63: 945-956.

Holvoet P, Vanhaecke J, Janssens S, Van de Werf F, Collen D (1998) Oxidized LDL and malondialdehyde-modified LDL in patients with acute coronary syndromes and stable coronary artery disease. Circulation 98: 14871494.

Holvoet P, Mertens A, Verhamme P, Bogaerts K, Beyens G, Verhaeghe R, Collen D, Muls E, Van de Werf F (2001)
Circulating oxidized LDL is a useful marker for identifying patients with coronary artery disease. Arterioscler Thromb Vasc Biol 21: 844-848.

Hulthe J, Fagerberg B (2002) Circulating oxidized LDL is associated with subclinical atherosclerosis development and inflammatory cytokines (AIR study). Arterioscler Thromb Vasc Biol 22: 1162-1167.

Kondo A, Muranaka Y, Ohta I, Notsu K, Manabe M, Kotani K, Saito K, Maekawa M, Kanno T (2001) Relationship between triglyceride concentrations and LDL size evaluated by malondialdehyde-modified LDL. Clin Chem 47: 893-900.

Mackness MI, Harty D, Bhatnagar D, Winocour PH, Arrol S, Ishola M, Durrington PN (1991) Serum paraoxonase activity in familial hypercholesterolaemia and insulin-dependent diabetes mellitus. Atherosclerosis 86: 193-199.

Mackness B, Durrington PN, Boulton AJM, Hine D, Mackness MI (2002) Serum paraoxonase activity in patients with type I diabetes compared to healthy controls. Eur $J$ Clin Invest 32: 259-264.

Mertens A, Holvoet P (2001) Oxidized LDL and HDL: antagonists in atherothrombosis. FASEB J 15: 2073-2084.

Parthasarathy S, Santanam N, Ramachandran S, Meilhac O (2000) Potential role of oxidized lipids and lipoproteins in antioxidant defense. Free Radic Res 33: 197-215.

Sampson MJ, Braschi S, Willis G, Astley SB (2005) Paraoxonase-1 (PON-1) genotype and activity and in vivo oxidized plasma low-density lipoprotein in type II diabetes. Clin Sci 109: 189-197.

Sigurdardottir V, Fagerberg B, Hulthe J (2002) Circulating oxidized low-density lipoprotein (LDL) is associated with risk factors of the metabolic syndrome and LDL size in clinically healthy 58-years-old men (AIR study). J Intern Med 252: 440-447.

Teiber JF, Draganov DI, La Du BN (2004) Purified human serum PON1 does not protect LDL against oxidation in the in vitro assays initiated with copper or AAPH. $J$ Lipid Res 45: 2260-2268.

Tomás M, Sentí M, García-Faria F, Vila J, Torrents A, Covas M, Marrugat J (2000) Effect of simvastatin therapy on paraoxonase activity and related lipoproteins in familial hypercholesterolemic patients. Arterioscler Thromb Vasc Biol 20: 2113-2119.

Topçuoğlu A, Uzun H, Aydin S, Kahraman N, Vehid S, Zeybek G, Topçuoğlu D (2005) The effect of hormone replacement therapy on oxidized low density lipoprotein levels and paraxonase activity in postmenopausal women. Tohoku J Exp Med 205: 79-86.

Toshima S, Hasegawa A, Kurabayashi M, Itabe H, Takano T, Sugano J, Shimamura K, Kimura J, Michishita J, Suzuki T, Nagai R (2000) Circulation oxidized low density lipoprotein levels. A biochemical risk marker for coronary heart disease. Arterioscler Thromb Vasc Biol 20: 2243-2247.

Ylä-Herttuala S, Palinski W, Rosenfeld ME, Parthasarathy S, Carew TE, Butler S, Witztum JL, Steinberg D (1989) Evidence for the presence of oxidatively modified low density lipoprotein in atherosclerotic lesions of rabbit and man. J Clin Invest 84: 1086-1095. 